\title{
Seleção assistida com uso de marcador molecular para resistência a potyvírus em pimentão
}

\author{
Douglas Willian Nogueira(1), Danilo Gustavo Nogueira(1), Wilson Roberto Maluf(2), Gabriel Mascarenhas Maciel(2), \\ Antônia dos Reis Figueira(3) e Cícero Beserra de Menezes ${ }^{(4)}$ \\ (1)Universidade Federal de Lavras (Ufla), Departamento de Biologia, Caixa Postal 3.037, CEP $37200-000$ Lavras, MG. \\ E-mail: douglagen@yahoo.com.br, asp.nogueira@yahoo.com.br (2)Ufla, Departamento de Agricultura. E-mail: wrmaluf@dag.ufla.br, \\ gabrielmascarenhasmaciel@yahoo.com.br ${ }^{(3)}$ Ufla, Departamento de Fitopatologia. E-mail: antonia@ufla.br (4)Embrapa Milho e Sorgo, Caixa \\ Postal 151, CEP 35701-970 Sete Lagoas, MG. E-mail: cicero@cnpms.embrapa.br
}

Resumo - O objetivo deste trabalho foi determinar a presença do alelo Pvr4, que confere resistência contra o PepYMV (Pepper yellow mosaic virus), em genótipos de pimentão comunmente encontrados no mercado brasileiro, com uso de um marcador molecular codominante tipo CAPS. A resistência ao PepYMV, nos genótipos CM-334-INRA, Myr-29 e em genótipos derivados do híbrido comercial Mônica-R, foi detectada como associada à banda de $444 \mathrm{pb}$, ligada ao alelo de resistência $P v r 4$. As plantas resistentes homozigotas ( $P v r 4 / P v r 4)$ mostraram uma banda de $444 \mathrm{pb}$, as suscetíveis $\left(P v r 4^{+} / P v r 4^{+}\right)$uma banda de $458 \mathrm{pb}$ e as resistentes heterozigotas $\left(\mathrm{Pvr}^{+} / \mathrm{Pvr} 4\right)$ mostraram as duas bandas. No entanto, no acesso resistente CM-334-UFV, nos híbridos Magali-R e Martha-R, assim como em populações derivadas desse acesso e desses híbridos, a resistência ao PepYMV não esteve associada ao marcador CAPS. O acesso CM-334-UFV ('Criollo de Morelos-334', de Viçosa, MG) distinguiu-se do CM-334-INRA ('Criollo de Morelos-334', da França); embora ambos os acessos tenham sido resistentes ao PepYMV, apenas em CM-334-INRA foi encontrada a associação da resistência com a banda de $444 \mathrm{pb}$.

Termos para indexação: Capsicum annuum, marcadores moleculares, seleção assistida, vírus.

\section{Marker-assisted selection for resistance to potyvirus in sweet pepper}

\begin{abstract}
The objective of this work was to determine the presence of the Pvr4 allele, which controls the resistance to the PepYMV (Pepper yellow mosaic virus), in sweet pepper genotypes commonly available in the Brazilian market, using a CAPS codominant molecular marker. The resistance to PepYMV, in the genotypes CM-334-INRA, Myr-29, and in genotypes derived from the hybrid Mônica-R, was found to be associated with the $444 \mathrm{bp}$ band linked to the resistance allele $P v r 4$. Homozygous resistant plants ( $P v r 4 / P v r 4$ ) showed a single band of $444 \mathrm{bp}$, the susceptible ones $\left(\mathrm{Pvr}^{+} / P v r 4^{+}\right)$showed a band of $458 \mathrm{bp}$, and the heterozygous resistant plants $\left(P v r 4^{+} / P v r 4\right)$ showed both bands. However, in the resistant accession CM-334-UFV, and in the hybrids Magali-R and Martha-R, as well as in populations derived from this accession and these hybrids, the resistance to PepYMV was not associated to the CAPS marker. The accession CM-334-UFV ('Criollo de Morelos-334' from Viçosa, MG, Brazil) was distinct from CM-334-INRA ('Criollo de Morelos-334', from France); although both accessions were resistant to PepYMV, the association of resistance with the 444 bp band was found only in CM-334-INRA.
\end{abstract}

Index terms: Capsicum annuum, molecular marker, assisted selection, virus.

\section{Introdução}

Apesar dos avanços na melhoria dos sistemas produtivos da cultura do pimentão, as doenças têm sido os principais entraves a um aumento mais expressivo da produção. Entre as principais doenças da cultura, estão as causadas por vírus dos gêneros Potyvirus, particularmente pela espécie PepYMV(Pepper yellow mosaic virus), que tem sido prioridade nos programas de melhoramento de pimentão no Brasil (Echer \& Costa,
2002; Maciel-Zambolim et al., 2004). Atualmente, o PepYMV ocorre naturalmente, nas principais regiões produtoras, e provoca a doença conhecida popularmente como mosaico-amarelo do pimentão. No Espírito Santo, este vírus foi relatado também em plantios comerciais de tomateiro (Maciel-Zambolim et al., 2004). A existência de variabilidade genética no gênero Capsicum tem permitido controlar com eficiência, via resistência, as doenças viróticas causadas pelo complexo potyvírus. Fontes de resistência têm 
se mostrado eficientes e duradouras em condições de inoculação artificial e no campo (Caranta et al., 1999; Echer \& Costa, 2002).

A resistência a potyvírus, no pimentão, pode ser controlada por um dos sete locos gênicos da série $p v r$ já identificados, aos quais os autores denominaram: pvr1, pvr2, pvr3, Pvr4, pvr5, pvr6 e Pvr7 (Caranta et al., 1999; Grube et al., 2000b; Parrela et al., 2002). A maioria desses alelos é resistente a duas ou mais espécies de potyvírus. Os alelos dominantes Pvr4 e $P v r 7$ conferem resistência a todos os patótipos das espécies conhecidas e testadas, tendo sido ambos mapeados no cromossomo 10 do pimentão (Caranta et al., 1999; Arnedo-Andrés et al., 2002). Entretanto, Pvr4 é originado de C. annuum, acesso CM-334 (Criollo de Morelos-334) e Pvr7 de C. chinense, acesso PI 159236(Grube et al., 2000a).

No Brasil, as fontes de resistência de amplo espectro à estirpe comum de PVY e à de PepYMV têm sido encontradas no acesso CM-334, em algumas linhagens, em híbridos comerciais e nas cultivares de polinização aberta Myr-29 e Myr-10. Entretanto, não se sabe ao certo a natureza da resistência encontrada nesses materiais, ou seja, se é conferida por um único loco ou por mais de um loco da série $p v r$ (Valle, 2001; Echer $\&$ Costa, 2002).

Com exceção do pvr3, todos os demais alelos da série $p v r$ estão associados a um ou mais marcadores moleculares, seja do tipo RFLP, ou obtidos a partir de cDNA. O alelo Pvr4, para cuja identificação se utilizavam, inicialmente, marcadores do tipo AFLP (Caranta et al., 1999; Arnedo-Andrés et al., 2002), foi convertido em marcador PCR com iniciadores específicos (Parrela et al., 2002). Desenvolvido por Caranta et al. (1999), o marcador PCR com iniciadores específicos é do tipo CAPS codominante, obtido a partir do cruzamento entre as cultivares Yolo Wonder (suscetível) e CM-334 (resistente), e determinado por meio da análise de bulk segregante associada a iniciadores de AFLP. Este marcador está a 2,1 $\pm 0,8$ cM do alelo Pvr4 e gera bandas de $458 \mathrm{pb}$ nos genótipos suscetíveis e $444 \mathrm{pb}$ nos resistentes, o que constitui uma importante ferramenta para identificação e seleção em diferentes genótipos. Presumivelmente, genótipos portadores de $P v r 4$ devem apresentar a banda correspondente a este alelo de resistência, descrito por Caranta et al. (1999), a menos que a ligação entre o gene Pvr4 tenha sido quebrada via recombinação na fonte original de resistência a potyvírus, ou em gerações posteriores. Além disso, Grube et al. (2000a) descreveram em $C$. chinense um outro gene de resistência a potyvírus, denominado $P v r 7$ e mapeado a cerca de $2 \mathrm{cM}$ de $P v r 4$, que não está aparentemente associado ao marcador CAPS.

Até o momento, não se sabe ao certo se as atuais cultivares híbridas, disponíveis e comercializadas pelas principais empresas no Brasil, bem como linhagens elites e progênies do Programa de Melhoramento Genético de Hortaliças da Ufla/HortiAgro Sementes S.A., todas resistentes a estirpes comuns de PVY e PepYMV, são portadoras ou não do alelo Pvr4 e de seu marcador CAPS, descrito por Caranta et al. (1999), visto que existem outros alelos, com modo distinto de ação, que podem também ser responsáveis pela expressão da resistência a isolados de potyvírus.

O objetivo do presente trabalho foi determinar a presença do alelo Pvr4, que confere resistência contra o PepYMV(Pepper yellow mosaic virus), em genótipos de pimentão comumente encontrados no mercado brasileiro, com uso de um marcador molecular codominante tipo CAPS (Caranta et al., 1999).

\section{Material e Métodos}

As avaliações da resistência dos genótipos ao potyvírus (PepYMV) foram realizadas em casa de vegetação, na área experimental da HortiAgro Sementes S.A., situada no Município de Ijaci, MG. A determinação da presença do alelo Pvr4, com o marcador molecular CAPS foi realizada no Laboratório de Virologia Molecular (LVM), do Departamento de Fitopatologia da Universidade Federal de Lavras.

Os materiais a serem testados foram semeados em bandejas de isopor de 128 células (16 x 8), com substrato comercial Plantimax, em delineamento inteiramente casualizado, com seis repetições, e as parcelas foram constituídas de oito plantas.

As inoculações do isolado do vírus e as avaliações de sintomas foram feitas em plantas mantidas nas bandejas. Para isso, foi utilizado um isolado, cedido pela Sakata Seed Sudamerica, Bragança Paulista, SP, coletado no Município de Lins, SP, proveniente de plantas de pimentão naturalmente infectadas, com sintoma sistêmico, e caracterizado sorologicamente. Para a manutenção do isolado, em condições de armazenamento, plantas de Nicotiana tabacum 
'TNN' e de pimentão da cultivar Ikeda, previamente infectadas com o isolado de PepYMV foram mantidas em dessecadores com sílica-gel e também em nitrogênio líquido, à temperatura controlada de $-80^{\circ} \mathrm{C}$ (ultra-freezer). A produção de inóculo, para posterior desafio dos genótipos de pimentão foi realizada a partir de plantas indicadoras de $N$. tabacum 'TNN', mantidas em estufas com telas; as plantas foram repicadas a intervalos de aproximadamente dois meses.

Para a avaliação da presença do gene Pvr4, com o marcador tipo CAPS, plantas dos genótipos de pimentão foram desafiadas individualmente, com um isolado de PepYMV. Para isso, utilizaram-se as plantas a seguir: cultivares comerciais, resistentes a PepYMV, 'Magali-R', híbrida, da Sakata Sudamerica, com procedência da resistência ao PepYMV não revelada; Konan-R, cultivar híbrida, HortiAgro/Agristar do Brasil, híbrido entre 'Myr-29' e uma linhagem suscetível a PepYMV; 'Myr-29', cultivar de polinização aberta, com procedência da resistência não conhecida; cultivar comercial Ikeda, suscetível ao PepYMV, de polinização aberta; linhagem resistente a PepYMV, PIM-025, com resistência obtida a partir do híbrido Magali-R; acessos resistentes a PepYMV, Criollo de Morelos CM-334-UFV, proveniente da Universidade Federal de Viçosa, cedido pela empresa Sakata Sudamerica e Criollo de Morelos CM-334-INRA, proveniente do Institut National de La Recherche Agronomique, cedido por Carole Caranta; e PIM-004, linhagem suscetível a PepYMV.

As populações $\left(\mathrm{F}_{1} \mathrm{RC}_{1}\right)$ experimentais, resistentes ao PepYMV, são: PIX-051 = \{[(PIM-025 x PIM-013) x PIM-025]\}, população $\mathrm{F}_{1} \mathrm{RC}_{1}$, em que o genitor recorrente é o PIM-025, linhagem resistente a PepYMV, obtida a partir do híbrido Magali-R, e o genitor não recorrente é o PIM-013, linhagem suscetível ao PepYMV; PIX-052 $=\{[($ PIM-023 x PIM-013) $\times$ PIM-023] $\}$, população $\mathrm{F}_{1} \mathrm{RC}_{1}$, em que o genitor recorrente é o PIM-023, linhagem resistente ao PepYMV, obtida a partir do híbrido Magali-R, e o genitor não recorrente é PIM-013, linhagem suscetível ao PepYMV; PIX-053= $\{[(\mathrm{Myr}-29 \times \mathrm{PIM}-013) \times \mathrm{Myr}-29]\}$, população $\mathrm{F}_{1} \mathrm{RC}_{1}$, em que o genitor recorrente é a 'Myr-29', resistente ao PepYMV, e o genitor não recorrente é o PIM-013, linhagem suscetível a PepYMV.

As populações $\left(\mathrm{F}_{2}\right)$ experimentais, segregantes quanto à resistência a PepYMV, são: PIX-044, população $F_{2}$ obtida a partir da autofecundação do híbrido Mônica-R (resistência proveniente de fonte não revelada); PIX-045, população $F_{2}$ obtida a partir da autofecundação do híbrido Martha-R (resistência proveniente de fonte não revelada).

Famílias derivadas da autofecundação de plantas resistentes ao PepYMV e portadoras do marcador CAPS, associado a esta resistência, foram testadas posteriormente tanto em relação à resistência ao vírus, quanto à presença do marcador.

$\mathrm{Na}$ avaliação das populações dos genótipos PIX-051, PIX-052 e PIX-053, o resultado esperado é de 100\% de plantas resistentes ao PepYMV naturalmente infectadas (das quais $50 \%$ homozigotas e $50 \%$ heterozigotas para o alelo de resistência). Para PIX-044 e PIX-045, espera-se $75 \%$ de plantas resistentes ao PepYMV (das quais $1 / 3$ homozigotas e $2 / 3$ heterozigotas para o alelo de resistência). De acordo com Caranta et al. (1999), se o alelo de resistência presente for o Pvr4, proveniente de Criollo de Morelos CM-334-INRA, as proporções esperadas também deverão ser aplicadas ao marcador CAPS, ligado ao alelo-alvo.

Os genótipos de pimentão foram semeados em bandejas de isopor de 128 células, e duas sementes foram depositadas em cada célula; após a germinação e emergência das plântulas, realizou-se o desbaste, tendo-se deixado apenas uma plântula por célula.

Para a inoculação, folhas de $N$. tabacum 'TNN', infectadas experimentalmente com o isolado do PepYMV, foram maceradas em tampão fosfato 0,01 mol L-1, pH 7,0. Em seguida, as plantas dos genótipos de pimentão a serem desafiadas foram polvilhadas com o abrasivo carborundum (400 mesh) sobre as folhas. Após a inoculação do vírus, as plantas foram lavadas com água e mantidas em estufa provida de cobertura de plástico e laterais teladas. Foram realizadas duas inoculações, para evitar possíveis escapes, em que a primeira foi realizada quando as plantas atingiram o estádio de desenvolvimento, com a primeira folha definitiva plenamente expandida; a segunda inoculação foi feita sete dias após a primeira. As avaliações foram feitas semanalmente, entre o $15^{\circ} \mathrm{e}$ $40^{\circ}$ dia após a primeira inoculação, o que totalizou cinco avaliações. Considerou-se como resultado final o $40^{\circ}$ dia de avaliação. Para cada planta das cultivares de pimentão desafiadas, foram atribuídas notas que variaram de 1 a 5 : 1, sem sintomas; 2 , clareamento internerval; 3 , mosaico leve; 4, mosaico bem desenvolvido, sem deformação foliar; 5, mosaico amarelo, bolhoso, com deformação 
foliar. Foram consideradas resistentes as plantas que na avaliação do $40^{\circ}$ dia, tiveram nota igual a 1,0.

Com base nos resultados da avaliação dos sintomas, realizou-se a extração de DNA. Nas populações $\left(\mathrm{F}_{2}\right)$ - PIX-044 e PIX-045 - , a extração foi realizada somente nas plantas que apresentaram características de resistência durante a avaliação dos sintomas.

Para as extrações de DNA, foram coletados folíolos, que foram acondicionados em envelopes de plástico devidamente identificados e mantidos em caixa de isopor, que continha gelo para reduzir a ocorrência de oxidação. A extração de DNA foi realizada em microtubos de $1,5 \mathrm{~mL}$, a partir de $120 \mathrm{mg}$ de tecido foliar, conforme Ferreira \& Grattapaglia (1998).

O marcador utilizado foi o CAPS (codominante), e o par de iniciadores utilizados para a PCR foi CSO-F (5'-CGAAGAGAGAAGGTC-3') e CSO-R (5'-TCAGGGTAGGTTATT-3'). A reação de PCR, a clivagem dos fragmentos amplificados e a eletroforese foram realizadas de acordo com Caranta et al. (1999). O DNA foi extraído de uma amostra de cada população e, com os resultados realizou-se a extração de um número maior de plantas, das populações portadoras do alelo $P v r 4$, para identificação de genótipos homozigotos resistentes (Pvr4/Pvr4).

Para determinar o reconhecimento do alelo $\mathrm{Pvr} 4$ pelo marcador CAPS, nos genótipos, híbridos e variedades de pimentão desafiadas com o isolado do PepYMV, foram utilizados os seguintes parâmetros: ligação entre o marcador e o alelo, com a visualização de um padrão de banda única de $458 \mathrm{pb}$, em plantas com genótipos presumivelmente suscetíveis homozigóticos $\left(P v r 4^{+} / P v r 4^{+}\right)$; ligação entre o marcador e o alelo, com a visualização de um padrão de banda única de $444 \mathrm{pb}$, em plantas com genótipos presumivelmente homozigotos resistentes ( $P v r 4 / P v r 4)$; ligação entre o marcador e o alelo, com a visualização de um padrão com duas bandas distintas de 458 pb e 444 pb, em plantas com genótipos presumivelmente resistentes heterozigotos $\left(P v r 4^{+} / P v r 4\right)$.

\section{Resultados e Discussão}

$\mathrm{Na}$ avaliação da reação ao PepYMV, as plantas suscetíveis de pimentão apresentaram clareamento internervais a mosaico. No final do período de experimento, $100 \%$ das plantas 'Ikeda' e da linhagem PIM-004 (ambas suscetíveis) apresentaram sintomas típicos da doença (mosaico amarelo, seguido ou não por deformação foliar, com notas médias superiores a 4,0). Comportamento variável foi observado entre plantas dentro das populações PIX-044 e PIX-045, o que se espera de populações segregantes quanto à resistência ao PepYMV. Nas cultivares comerciais, consideradas resistentes ao PepYMV (Magali-R, Konan-ReMyr-29), assimcomo nalinhagem PIM-025, nos acessos (CM-334-UFV e CM-334-INRA) e nas populações $\mathrm{F}_{1} \mathrm{RC}_{1}$ (PIX-051, PIX-052 e PIX-053), não foi observada nenhuma planta com sintomas. Em trabalho de avaliação de genótipos resistentes ao PepYMV, Nascimento et al. (2007) obtiveram resultados similares para os mesmos genótipos.

O marcador molecular CAPS foi eficiente em distinguir, nas populações derivadas da cultivar resistente Myr-29, plantas resistentes homozigotas Pvr4/Pvr4 de plantas heterozigotas $\mathrm{Pvr}^{+} / \mathrm{Pvr} 4$ ou suscetíveis $P v r 4^{+} / P v r 4^{+}$(Figura 1). Em 'Myr-29', plantas resistentes apresentaram uma banda de $444 \mathrm{pb}$, que caracteriza os genótipos homozigotos resistentes (Pvr4/Pvr4); plantas suscetíveis (Ikeda) apresentaram uma banda de $458 \mathrm{pb}$, característica dos

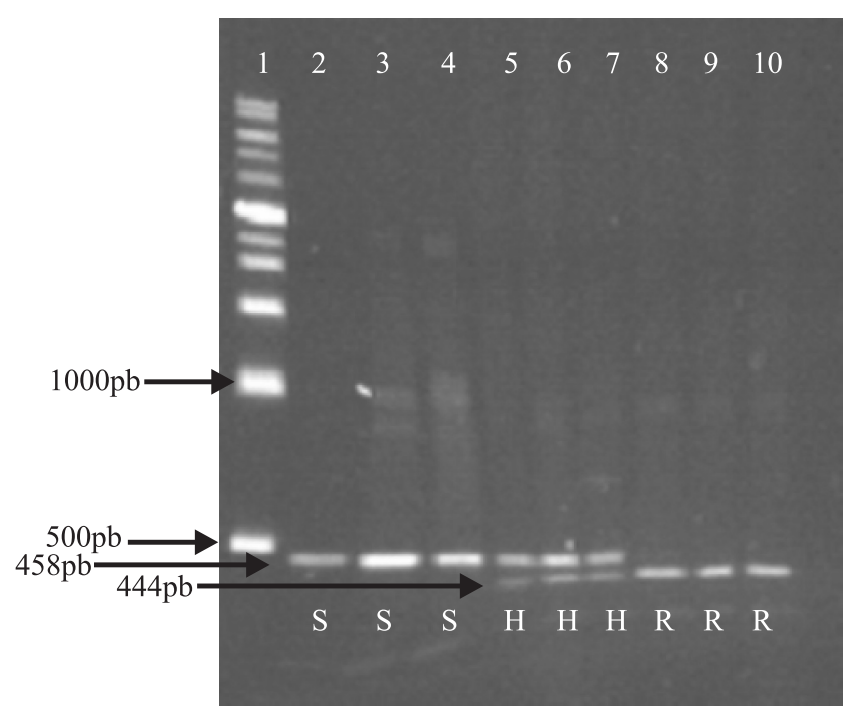

Figura 1. Padrão eletroforético de fragmentos de DNA, amplificados com o marcador CAPS, em plantas de pimentão: 1, ladder (500 pb) (Invitrogen Co., Carlsbad, CA, EUA); 2, Ikeda pl\#1; 3, Ikeda pl\#2; 4, Ikeda pl\#3; 5, Konan-R pl\#1; 6, Konan-R pl\#2; 7, Konan-R pl\#3; 8, Myr-29 pl\#1; 9, Myr-29 pl\#2; 10, Myr-29 pl\#3. S, suscetível; R, resistente; $\mathrm{H}$, heterozigoto (para o loco do alelo Pvr4) 
genótipos homozigotos suscetíveis $\left(\mathrm{Pvr}^{+} / \mathrm{Pvr4^{+ }}\right)$; o híbrido resistente Konan-R, sabidamente heterozigoto, mostrou as duas bandas que caracterizam os genótipos resistentes heterozigotos $\left(\mathrm{Pvr}^{+} / \mathrm{Pvr} 4\right)$ (Caranta et al., 1999).

A distância de apenas $2,1 \pm 0,8 \mathrm{cM}$, entre o marcador CAPS e o gene com o alelo Pvr4, permite selecionar, com boa margem de segurança, plantas resistentes a PepYMV, tanto com base na seleção assistida como em populações cuja fonte de resistência ao PepYMV seja proveniente da cultivar Myr-29 (Caranta et al., 1999). Das cinco plantas previamente selecionadas como resistentes ao PepYMV e analisadas com o marcador na população $\mathrm{F}_{1} \mathrm{RC}_{1}$ PIX-053, três apresentaram bandas correspondentes ao genótipo heterozigoto e duas apresentaram a banda correspondente ao genótipo homozigoto resistente com o alelo Pvr4 (Figura 2). Com esses resultados, confirmou-se a eficiência do marcador em selecionar genótipos portadores do alelo Pvr4, pois as populações $\mathrm{F}_{1} \mathrm{RC}_{1}$ PIX-053 teve como pai recorrente a cultivar Myr-29 e, portanto, as plantas desse retrocruzamento comportaram-se como portadoras do alelo Pvr4 e seu marcador, seja em homozigose (banda de $444 \mathrm{pb}$ ) ou heterozigose (bandas de $444 \mathrm{pb}$ e de $458 \mathrm{pb}$ ).

Famílias distintas de genótipos de pimentão foram obtidas a partir da autofecundação de plantas resistentes ao PepYMV. A população PIX-053 foi caracterizada como portadora do alelo Pvr4, com formação de banda de $444 \mathrm{pb}$, seja em homozigose (Pvr4/Pvr4) ou heterozigose $\left(P v r 4^{+} / P v r 4\right)$. A família PIX-053A-01, derivada de planta resistente, previamente identificada como portadora das bandas de 444 e 458 pb, também foi avaliada, bem como as famílias PIX-053A-03 e PIX-053A-04, derivadas de plantas previamente identificadas como portadoras apenas da banda de $444 \mathrm{pb}$.

Após a inoculação do vírus e extração de DNA (amostras), observou-se a ausência de plantas com sintomas típicos da doença nas famílias PIX-053A-03 e PIX-053A-04, e a análise feita com o marcador revelou apenas a presença da banda de $444 \mathrm{pb}$, correspondente ao genótipo homozigoto $P v r 4 / P v r 4$ (Figura 3 ), o que era esperado, pois as plantas que originaram tais famílias eram presumivelmente homozigotas resistentes (Pvr4/Pvr4). Plantas dentro das famílias PIX-053A-01

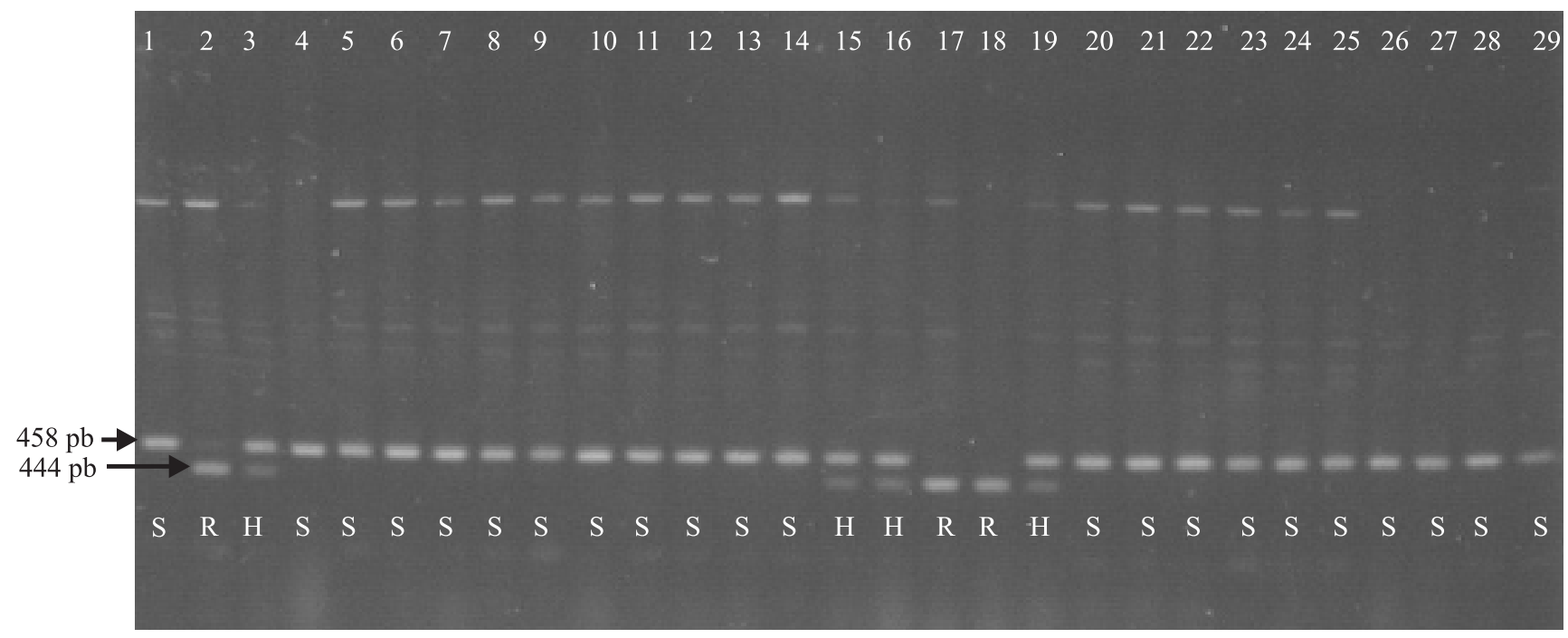

Figura 2. Padrão eletroforético de fragmentos de DNA, amplificados com o marcador CAPS, em plantas de pimentão: 1, Ikeda pl\#1; 2, Myr-29 pl\#1; 3, Konan-R pl\#1; 4, PIM-004 pl\#1; 5, PIM-004 pl\#2; 6, PIM-004 pl\#3; 7, PIM-004 pl\#4; 8,

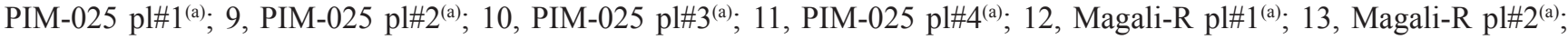
14, Magali-R pl\#3 ${ }^{(\mathrm{a})} ; 15$, PIX-053 pl\#1; 16, PIX-053 pl\#2; 17, PIX-053 pl\#3; 18, PIX-053 pl\#4; 19, PIX-053 pl\#5; 20 ,

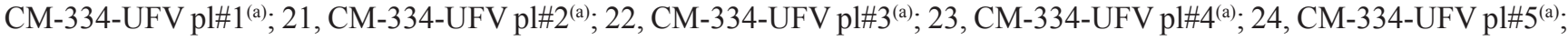

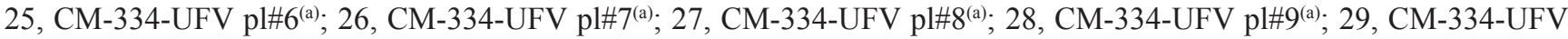

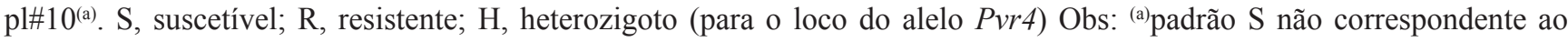
fenótipo da planta (resistente a PepYMV). 
apresentaram segregação, tanto na avaliação fenotípica (inoculação), quanto na genotípica (marcador), pois tal família foi originada a partir da planta heterozigota $\left(P v r 4^{+} / P v r 4\right)$.

Na população PIM-004, todas as plantas avaliadas apresentaram banda correspondente ao genótipo homozigoto suscetível no loco do alelo Pvr4 (Figura 2), o que confirma a avaliação fenotípica da reação a PepYMV.

Quando testadas com o marcador CAPS, as plantas confirmadas como resistentes ao PepYMV, do híbrido Magali-R, do acesso CM-334-UFV, da linhagem PIM-025 e das populações PIX-051 e PIX-052, apresentaram o padrão correspondente à banda de $458 \mathrm{pb}$. Nestes casos, o alelo de resistência ao PepYMV não está associado à banda de 444 pb e, com o marcador CAPS, todas as plantas analisadas mostraram um padrão de suscetibilidade ao vírus que não corresponde ao fenótipo (resistente) observado (Figuras 2, 4 e 5). O fato de as plantas do acesso Criollo de Morelos CM-334-UFV mostrarem um padrão de suscetibilidade com o marcador CAPS é uma indicação de que a origem desse acesso não corresponde à mesma do 'CM-334' descrita por Caranta et al. (1999), considerado resistente a potyvírus e portador da banda de $444 \mathrm{pb}$ associada a esta resistência. Os resultados do presente ensaio confirmam a não identidade entre os dois acessos, pois plantas do acesso CM-334-INRA (cedido por Caranta/ INRA), quando testadas com o marcador CAPS, apresentaram a banda de $444 \mathrm{pb}$ correspondente ao genótipo homozigoto Pvr4/Pvr4 (Figura 5). É possível que, no acesso CM-334-UFV, o alelo Pvr4 não esteja associado à banda de $444 \mathrm{pb}$ ou mesmo que sua resistência ao PepYMV seja controlada por outro gene que não o Pvr4. No entanto, embora a origem da resistência do pimentão 'Magali-R' não tenha sido revelada, é possível que esta resistência seja originária do acesso CM-334-UFV, e não do 'CM-334' de Caranta et al. (1999), o que explicaria o fato de CM-334-UFV, 'Magali-R', a linhagem e as populações destes derivadas (linhagem PIM-025 e populações PIX-051 e PIX-052) não apresentarem a banda de $444 \mathrm{pb}$, associada ao alelo Pvr4, embora sejam resistentes ao PepYMV (Figuras 2 e 4). A hipótese de $P v r 7$ ou outro gene - não associado à banda de 444 pb do marcador CAPS (Grube et al., 2000a) - ser ou não ser responsável pela resistência

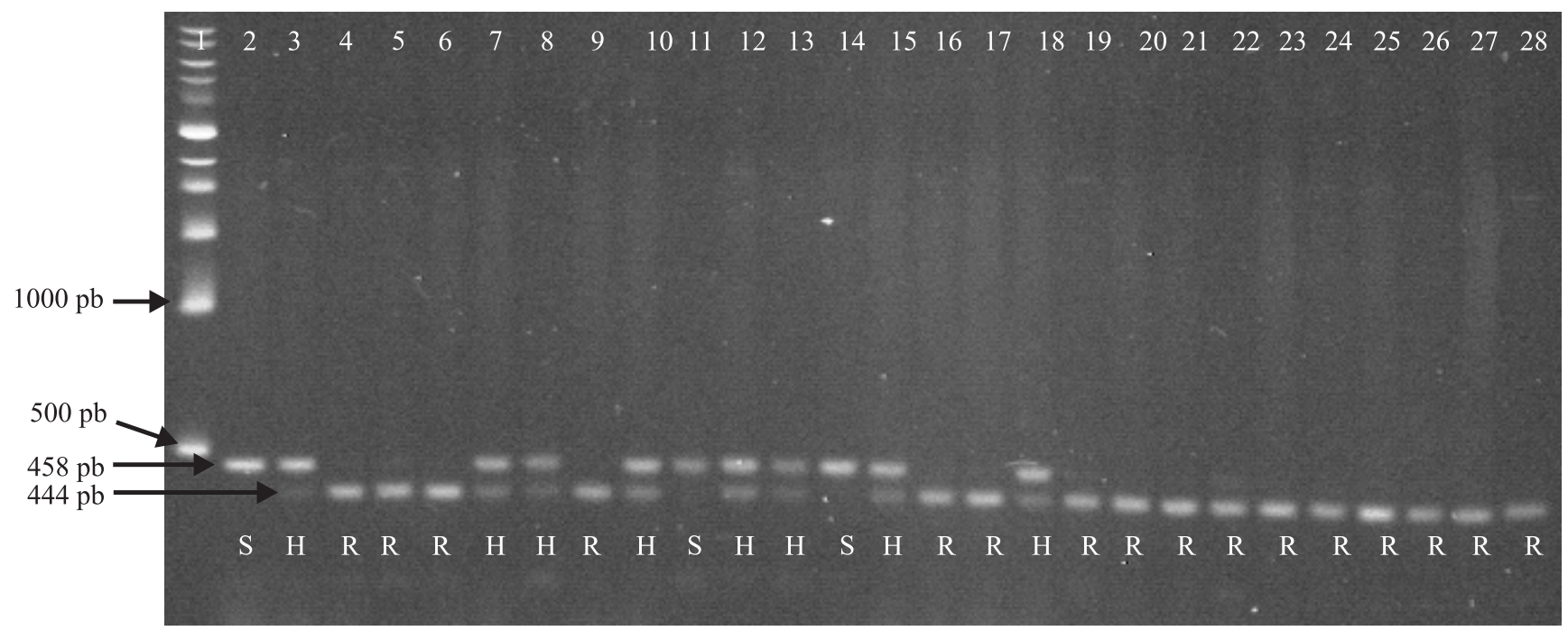

Figura 3. Padrão eletroforético de fragmentos de DNA, amplificados com o marcador CAPS, em plantas de pimentão: 1, ladder (500 pb) (Invitrogen Co., Carlsbad, CA, EUA); 2, Ikeda pl\#3; 3, Konan-R pl\#3; 4, Myr-29 pl\#3; 5, PIX-044A-05 pl\#1; 6, PIX-044A-05 pl\#2; 7, PIX-044A-05 pl\#3; 8, PIX-044A-05 pl\#4; 9, PIX-044A-05 pl\#5; 10, PIX-044A-05 pl\#6; 11, PIX-044A-05 pl\#7; 12, PIX-053A-01 pl\#1; 13, PIX-053A-01 pl\#2; 14, PIX-053A-01 pl\#3; 15, PIX-053A-01 pl\#4; 16, PIX-053A-01 pl\#5; 17, PIX-053A-01 pl\#6; 18, PIX-053A-01 pl\#7; 19, PIX-053A-03 pl\#1; 20, PIX-053A-03 pl\#2; 21, PIX-053A-03 pl\#3; 22, PIX-053A-03 pl\#4; 23, PIX-053A-03 pl\#5; 24, PIX-053A-04 pl\#1; 25, PIX-053A-04 pl\#2; 26, PIX-053A-04 pl\#3; 27, PIX-053A-04 pl\#4; 28, PIX-053A-04 pl\#5. S, suscetível; R, resistente; H, heterozigoto (para o loco do alelo Pvr4). 
a potyvírus em CM-334-UFV e 'Magali-R' e seus derivados é algo que ainda precisa ser investigado.

Em plantas resistentes a potyvírus, na população segregante PIX-044 ( $\mathrm{F}_{2}$ do híbrido Mônica-R), observou-se um padrão de banda que corresponde ao genótipo homozigoto (Pvr4/Pvr4) e um padrão que corresponde ao genótipo heterozigoto $\left(P v r 4^{+} / P v r 4\right)$ (Figura 4). Isto mostra que a seleção fenotípica foi eficiente e, também, que a resistência a PepYMV, encontrada no híbrido Mônica-R, se deve ao alelo Pvr4, neste caso, associado à banda de $444 \mathrm{pb}$ do marcador CAPS. A exemplo do relatado anteriormente, sobre a população PIX-053, plantas testadas como resistentes ao PepYMV na população PIX-044, identificadas como portadoras do alelo Pvr4 e das marcas de $444 \mathrm{pb}$ e 458 pb, foram autofecundadas para obtenção de famílias. A família PIX-044A-05 apresentou segregação tanto na avaliação fenotípica (inoculação), quanto na genotípica (marcador) (Figura 3), pois foi derivada de planta resistente previamente identificada como heterozigota $\left(\mathrm{Pvr}^{+} / \mathrm{Pvr} 4\right)$.

Nas plantas resistentes ao PepYMV, da população segregantePIX-045 ( $\mathrm{F}_{2}$ do híbrido Martha-R), observouse um padrão de banda correspondente a um padrão de suscetibilidade ao vírus, mas que não corresponde ao fenótipo (resistente) observado, ou seja, à presença da banda de $458 \mathrm{pb}$ somente (Figura 4). A exemplo do que se concluiu para CM-334-UFV, 'Magali-R' e seus derivados, em 'Martha-R', o alelo Pvr4 ou não está associado à banda de $444 \mathrm{pb}$, ou a resistência ao PepYMV é controlada por um outro gene que não o Pvr4 (Grube et al., 2000a).

Entre as diversas vantagens da seleção assistida por marcadores moleculares, podem ser citadas a ausência de efeitos ambientais e a independência do estádio de desenvolvimento da planta, ambas consideradas por alguns autores como alguns dos principais problemas, quando se deseja selecionar plantas resistentes ou imunes a viroses, via seleção fenotípica (Lanza et al., 2000). Muitos marcadores moleculares associados a genes de resistência a viroses têm sido desenvolvidos, porém sua utilização não é frequente, pois, na maioria das vezes, não estão ligados muito próximos aos genes de interesse (Silva et al., 2003; Santos, 2004). Este não é o caso do alelo Pvr4 (Caranta et al., 1999). Além da grande importância na identificação de materiais homozigotos resistentes, esse marcador CAPS, associado a $P v r 4$, possibilitará a piramidação de genes de resistência ao PepYMV.

A resistência ao PepYMV no acesso CM-334-INRA, na cultivar Myr-29 e em materiais derivados do híbrido comercial Mônica-R foi detectada como associada à

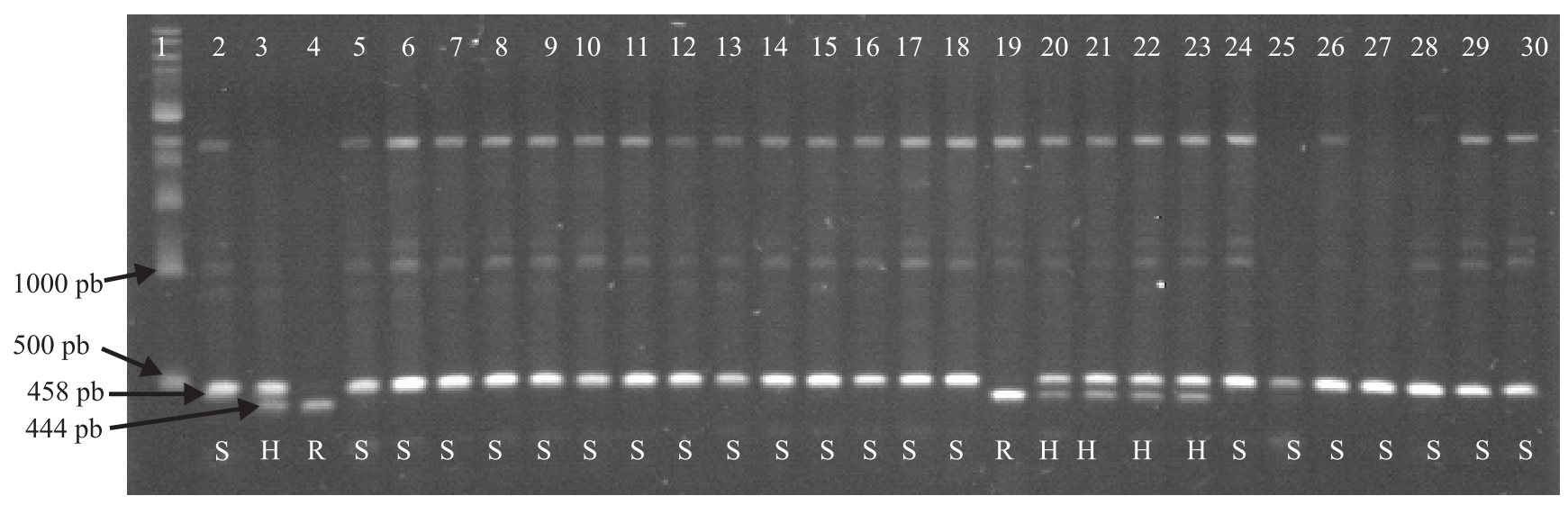

Figura 4. Padrão eletroforético de fragmentos de DNA, amplificados com o marcador CAPS, em plantas de pimentão: 1, ladder (500 pb) (Invitrogen Co., Carlsbad, CA, EUA); 2, Ikeda pl\#2; 3, Konan-R pl\#2; 4, Myr-29 pl\#2 5, PIX-051 pl\#1 (a);

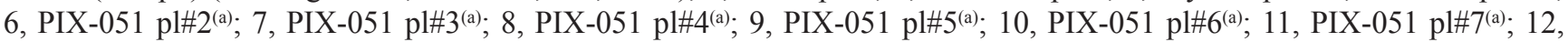

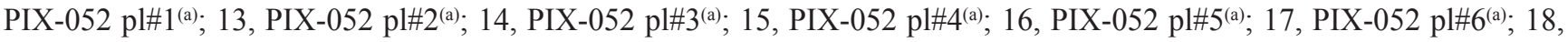
PIX-052 pl\#7(a); 19, PIX-044 pl\#1; 20, PIX-044 pl\#2; 21, PIX-044 pl\#3; 22, PIX-044 pl\#4; 23, PIX-044 pl\#5; 24, PIX-045

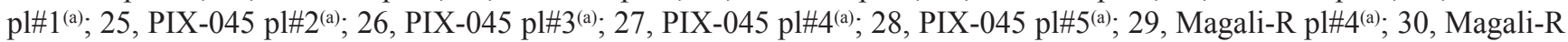
pl\#5 (a) S, suscetível; R, resistente; $\mathrm{H}$, heterozigoto (para o loco do alelo Pvr4). Obs: (a) padrão $\mathrm{S}$ não correspondente ao fenótipo da planta (resistente a PepYMV). 


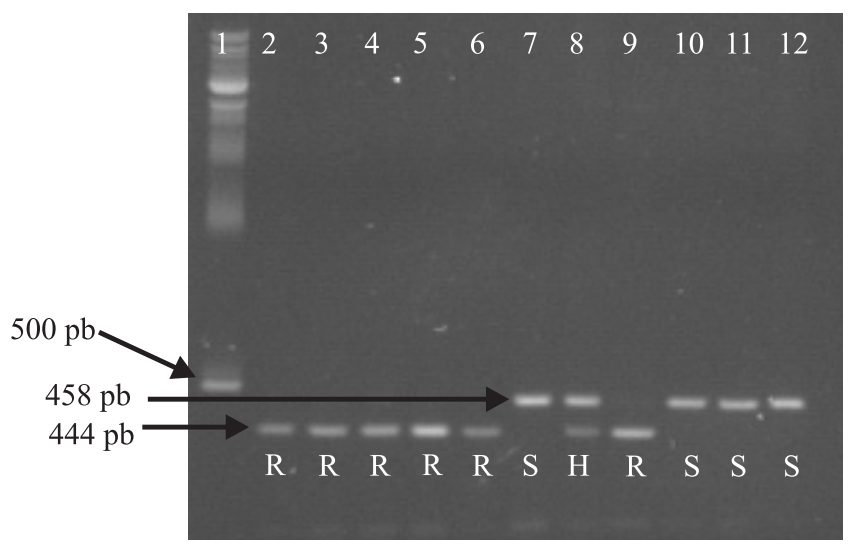

Figura 5. Padrão eletroforético de fragmentos de DNA, amplificados com o marcador CAPS em plantas de pimentão: 1- ladder (500 pb) (Invitrogen Co., Carlsbad, CA, EUA); 2, CM 334-INRA pl\#1; 3, CM-334-INRA pl\#2; 4, CM-334-INRA pl\#3; 5, CM-334-INRA pl\#4; 6, CM-334-INRA pl\#5; 7, Ikeda pl\#1; 8, Konan-R pl\#1; 9, Myr-29 pl\#1; 10, CM-334-UFV pl\#11 ${ }^{\text {(a) }}$; 11, CM-334-UFV pl\#12 ${ }^{\text {(a) }} ; 12, \mathrm{CM}-334-U F V$ pl\#13 ${ }^{(\mathrm{a})}$. S, suscetível; R, resistente; $\mathrm{H}$, heterozigoto (para o loco do alelo Pvr4). Obs: ${ }^{\text {a) }}$ padrão $\mathrm{S}$ não correspondente ao fenótipo da planta (resistente a PepYMV).

banda de $444 \mathrm{pb}$ do marcador, descrito por Caranta et al. (1999) como ligado ao alelo de resistência Pvr4. Contudo, no acesso resistente CM-334-UFV, nos híbridos Magali-R, Martha-R e nas populações destes derivadas, a resistência ao PepYMV não esteve associada à presença do mesmo marcador, o que indica que, nestes materiais, o alelo $P v r 4$ ou não está associado à banda de $444 \mathrm{pb}$, ou sua resistência ao PepYMV é controlada por um outro gene que não o Pvr4.

\section{Conclusões}

1. O marcador molecular do tipo CAPS é eficiente em selecionar plantas resistentes, portadoras do alelo Pvr4, em populações cuja resistência é derivada da cultivar Myr-29 ou do híbrido Mônica-R.

2. A cultivar comercial Myr-29, o acesso CM-334-INRA e os híbridos Konan-R e Mônica-R são portadores do alelo de resistência $P v r 4$, associado a um marcador molecular tipo CAPS (banda de $444 \mathrm{pb}$ ).
3. A resistência a potyvírus em CM-334-UFV, 'Magali-R' (e seus derivados) ou 'Marta-R' não está associada ao marcador molecular CAPS que se mostra, portanto, inapropriado para a seleção de plantas resistentes ao PepYMV, em populações derivadas destes materiais.

\section{Agradecimentos}

À Fundação deAmparoà Pesquisa do Estado deMinas Gerais, ao Conselho Nacional de Desenvolvimento Científico e Tecnológico e à Coordenação de Aperfeiçoamento de Pessoal de Nível Superior, pela concessão de bolsas; à Universidade Federal de Lavras - Fundação de Apoio ao Ensino, Pesquisa e Extensão, Fundação de Desenvolvimento Científico e Cultural, e Laboratório de Virologia Molecular -, pelos recursos financeiros e infraestrutura; à empresa HortiAgro Sementes S.A., pelo apoio na realização do experimento; à pesquisadora Carole Caranta, Institut National de la Recherche Agronomique, pelo fornecimento de sementes.

\section{Referências}

ARNEDO-ANDRÉS, M.S.; GIL-ORTEGA, R.; LUIS-ARTEAGA, M.; HORMAZA, J.I. Development of RAPD and SCAR markers linked to the Pvr4 locus for resistance to PVY in pepper (Capsicum annum L.). Theoretical and Applied Genetics, v.105, p.1067-1074, 2002.

CARANTA, C.; THABUIS, A.; PALLOIX, A. Development of a CAPS marker for the Pvr4 locus: a tool for pyramiding potyvirus resistance genes in pepper. Genome, v.42, p.1111-1116, 1999.

ECHER, M. de M.; COSTA, C.P. da. Reaction of sweet pepper to the potato virus $Y\left(\mathrm{PVY}^{\mathrm{m}}\right)$. Scientia Agricola, v.59, p.309-314, 2002.

FERREIRA, M.E.; GRATTAPAGLIA, D. Introdução ao uso de marcadores moleculares em análise genética. 3.ed. Brasília: Embrapa-Cenargen, 1998.220p. (Embrapa-Cenargen. Documentos, 20).

GRUBE, R.C.; BLAUTH, J.R.; ARNEDO-ANDRÉS, M.S.; CARANTA, C.; JAHN, M. Identification and comparative mapping of dominant potyvirus resistance gene cluster in Capsicum. Theoretical and Applied Genetics, v.101, p.852-859, 2000a.

GRUBE, R.C.; RADWANSKI, E.R.; JAHN, M. Comparative genetics of disease resistance within the Solanaceae. Genetics, v. 155, p.873-887, 2000b.

LANZA, M.A.; GUIMARÃES, T.C.; SHUSTER, I. Aplicação de marcadores moleculares no melhoramento genético. Informe Agropecuário, v.21, p.97-108, 2000. 
MACIEL-ZAMBOLIM, E.; COSTA, H.; CAPUCHO, A.S.; ÁVILA, A.C. de; INOUE-NAGATA, A.K.; KITAGIMA, E.W. Surto epidemiológico do vírus do mosaico amarelo do pimentão em tomateiro na região serrana do Espírito Santo. Fitopatologia Brasileira, v.29, p.325-327, 2004.

NASCIMENTO, I.R. do; VALE, L.A.C. do; MALUF, W.R.; GONÇALVES, L.D.; GOMES, L.A.A.; MORETO, P.; LOPES, E.A. das G.L. Reação de híbridos, linhagens e progênies de pimentão à requeima causada por Phytophthora capsici e ao mosaico amarelo causado por Pepper yellow mosaic virus (PepYMV). Ciência e Agrotecnologia, v.31, p.121-128, 2007.

PARRELA, G.; RUFFEL, S.; MORETTI, A.; MOREL, C. Recessive resistance genes against potyviruses are localized in collinear genomic regions of the tomato (Lycopersicon spp.) and pepper (Capsicum spp.) genomes. Theoretical and Applied Genetics, v.105, p.855-861, 2002.
SANTOS, R.C. Reação de cultivares de soja aos vírus do amarelo do broto (Soyben yellow shoot vírus- SYSV) e do mosaico da soja (Soybean mosaic virus- SMV) e seleção de marcadores SSR para identificação do alelo de resistência ao SYSV. 2004. 77p. Tese (Doutorado) - Universidade Federal de Lavras, Lavras.

SILVA, G.F. da; SANTOS, J.B. dos; RAMALHO, M.A.P. Identification of SSR and RAPD markers linked to a resistance allele for angular leaf spot in the common bean (Phaseolus vulgaris) line ESAL 550. Genetics and Molecular Biology, v.26, p.459-463, 2003.

VALLE, L.A.C. Análise genética e identificação de regiões genômicas que conferem resistência a Phytophthora capsici em Criollo de Morellos 334 (Capsicum annuum). 2001. 85p. Tese (Doutorado) - Universidade Federal de Viçosa, Viçosa.

Recebido em 9 de fevereiro de 2011 e aprovado em 23 de maio de 2012 